\title{
THE USE OF RADIOACTIVE CARBON DIOXIDE TO MEASURE REGIONAL BLOOD FLOW IN THE LUNGS OF PATIENTS WITH PULMONARY DISEASE
}

\author{
By J. B. WEST, C. T. DOLLERY AND P. HUGH-JONES \\ (From the Department of Medicine, Postyraduate Medical School, Hammersmith Hospital, \\ London, England)
}

(Submitted for publication August 10, 1960; accepted September 2, 1960)

The short-lived radioactive isotope, oxygen ${ }^{15}$, can be used to measure the ventilation and blood flow in small regions of the lung without intubation of a patient $(1,2)$. The patient takes a single breath of air containing a minute amount of the active gas and breath-holds for 15 seconds, while scintillation counters aligned in front of and behind the chest detect the activity within the lung. The initial counting rate is determined by the ventilation of the lung core in the counting field. The fall in counting rate depends upon two factors: first, the transfer of the radioactive gas from alveolar gas to pulmonary capillary blood, and second, its removal from the counting field by the local blood flow.

When oxygen ${ }^{15}$ is used as molecular oxygen, the initial transfer into the pulmonary capillary blood depends upon the local oxygen uptake (3). If the isotope is used to label carbon monoxide (4), its initial transfer is limited by the local diffusing properties of the lung. By converting the radioactive oxygen into carbon dioxide (5) which diffuses very readily, the transfer from alveolar gas to pulmonary capillary blood becomes exceedingly rapid. For all three gases, the fall in counting rate during the breath-holding period is influenced by the removal rate of blood from the counting field, but for carbon dioxide, this becomes the only significant factor. The present paper reports measurements made on 30 patients with various pulmonary diseases in whom regional blood flow was measured with radioactive carbon dioxide. The carbon dioxide measurements are also compared with the corresponding radioactive oxygen and carbon monoxide measurements in the same regions of the lung.

\section{METHODS}

Oxygen $^{15}$ was prepared in the Medical Research Coun(il cyclotron in the grounds of Hammersmith Hospital by bombarding nitrogen with deuterons. The isotope has a half-life of only 2 minutes and it was therefore produced by a continuous flow process and pumped to a nearby clinical investigation room. Details of its preparation and purification have been published $(1,2)$. When the isotope was used as molecular oxygen, the gas was simply diluted about 20 times with air. To convert it into carbon monoxide, it was passed over heated carbon at $900^{\circ} \mathrm{C}$, and any carbon dioxide formed was removed with soda lime. To prepare carbon dioxide, the gas was passed over heated carbon at $450^{\circ} \mathrm{C}$ and then over heated copper oxide at $800^{\circ} \mathrm{C}$. The first process converted all the oxygen to a mixture of carbon dioxide and carbon monoxide, and the second removed the carbon monoxide. Periodical analyses for purity were made by using a mass spectrometer and an infrared analyzer.

The activity of the diluted gases was continuously monitored by a re-entrant ionization chamber and was approximately $5 \mathrm{mc}$ per $\mathrm{L}$. The maximal radiation dose to the blood or to any part of the body for 6 breaths of $1 \mathrm{~L}$ each is less than 400 mrads for radioactive oxygen and carbon monoxide, and less than 500 mrads for radioactive carbon dioxide. This dose is a little more than the weekly dose generally allowed for workers intermittently exposed to radiation but is small compared with the dose given by many special radiographic procedures such as screening, angiography and so forth.

The procedure was similar to that described previously (2). The patient was seated and took a rapid inspiration of $1 \mathrm{~L}$ of active gas from a plastic bag on the inspiratory side of a valve box with a low dead space. After 10 to 15 seconds of breath-holding he breathed room air, and the expired gas was piped from the room. Two pairs of counters were arranged, fore and aft, over each lung and the counting rates for the left and right pairs were displayed on two pen recorders. Figure 1 shows the tracings from a normal subject who inhaled a single breath of air containing radioactive carbon dioxide. The lefthand counters were at the level of the second rib, and those on the right were opposite the fifth rib anteriorly. The rapid initial deflection of the pens as the active gas entered the lung fields can be seen. The height of this initial deflection depends upon the length of the lung core in the counting field and on its ventilation. In this tracing, because the counters were at different levels where the lung cores had different length, the relative ventilations are not easily compared. In the measure ments on the patients, both pairs of counters were placed 


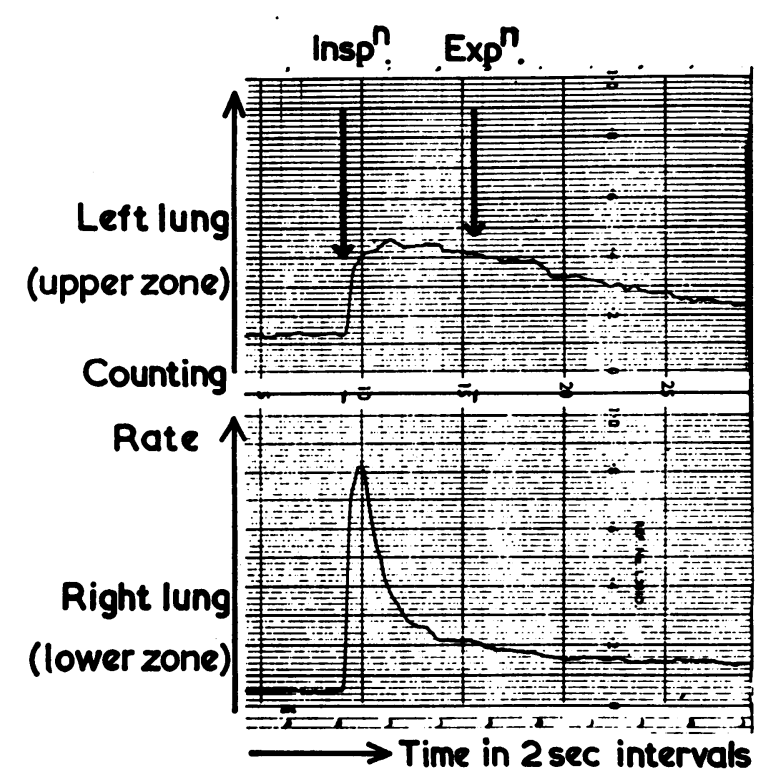

Fig. 1. Tracings from a Normal subject obtained WITH RAdIOACTIVE CARBoN DIOXIDE. The left-hand counters were at the level of the second rib and those on the right were opposite the fifth rib anteriorly. The striking difference in blood flow between the upper and lower zones of the lung can be seen.

at the same vertical level and at the same distance from the sternum. When examining the upper lung zones, the counters were centered over the midclavicular line. For lower zone measurements, the counter centers were separated by about $18 \mathrm{~cm}$ in order to exclude the heart from the counting field as far as possible. When the counters were symmetrically placed in this way, the height of the initial deflection was taken to be proportional to the ventilation of the lung core examined.

During the breath-holding period, the counting rate fell on both sides but the very slow fall at the left upper zone contrasts with the rapid fall at the right lower zone. The rate of fall is taken to be proportional to the blood flow of the lung core examined, and it can be shown that this steadily increases as the counters are moved down the normal chest (5). The fall in counting rate of carbon dioxide and carbon monoxide is exponential so that the slopes were replotted on semilogarithmic paper and the clearance rates expressed in per cent per second of the instantaneous activity. Appropriate corrections were made for the background and the natural decay of the isotope. The oxygen tracings have an approximately linear slope during the breath-holding and the clearance rate was expressed in per cent per second of the initial counting rate.

The time constant of a pair of counters with its amplifiers and pen recorder was 0.5 second and the ratemeter integrating time was 0.2 second. All the measurements were made with the comters connected in parallel, when the anteroposterior cylindrical core of lung from which 95 per cent of the counts was accepted was $9 \mathrm{~cm}$ in diameter (Figures 3-7). A smaller counting field can be effected by connecting the counters in coincidence, but then the lower counting rates result in poorer repeatability of the measurements.

In order to define normal values for all 3 gases on the same group of subjects measurements were made on 10 healthy volunteers who were members of the hospital staff. Six breaths on each subject were given, and in all, 4 vertical counter positions were used. These were at the level of the second rib anteriorly and 2, 4 and 5 inches below this. The first breath on one normal subject was excluded because the radioactive carbon dioxide clearance rates were considerably higher than in the second breath when the subject's pulse rate had slowed (see Discussion). The results are summarized in Table I.

Thirty patients with various pulmonary diseases were studied. In 4 patients the pulmonary vessels were primarily affected by emboli, thrombosis or unknown causes. Ten patients had localized cysts, bullae or areas of transradiancy, and there were 2 cases of unilateral transradiancy as described by Macleod (6). A further 10 patients had localized fibrosis caused by old infection, radiation or pneumoconiosis. Cases of bronchial carcinoma, pleural effusion and bronchiectasis also were studied.

\section{RESULTS}

Figure 2 shows a tracing obtained from a 12 year old boy who had clinical and angiographic evidence of an absent left pulmonary artery. In addition he had a ventricular septal defect. The counters were placed at the level of the second intercostal space and each pair was $7 \mathrm{~cm}$ from the mid-line. The rapid initial deflections of the pens as the patient breathed-in the radioactive carbon dioxide can be seen. Since the cores of the lung tissue in the counting fields were of the same length, the initial counting rates were proportional

TABLE I

Clearance rates of radioactive carbon dioxide, oxygen, and carbon monoxide in 10 healthy volunteers measured in the sitting position

\begin{tabular}{|c|c|c|c|}
\hline & $\begin{array}{l}\text { Carbon } \\
\text { dioxide }\end{array}$ & $\begin{array}{l}\text { Carbon } \\
\text { monoxide }\end{array}$ & Oxygen \\
\hline Second rib anteriorly & $\begin{array}{c}\% / \sec \\
4.8 \\
(2.1)\end{array}$ & $\begin{array}{c}\% / \mathrm{sec} \\
2.9 \\
(0.8)\end{array}$ & $\begin{array}{c}\% / \mathrm{sec} \\
0.5 \\
(0.1)\end{array}$ \\
\hline Below second rib, 2 in. & $\begin{array}{l}12.0 \\
(1.6)\end{array}$ & $\begin{array}{c}6.0 \\
(0.6)\end{array}$ & $\begin{array}{c}1.2 \\
(0.3)\end{array}$ \\
\hline Below second rib, 4 in. & $\begin{array}{l}23.5 \\
(1.7)\end{array}$ & $\begin{array}{c}8.9 \\
(0.8)\end{array}$ & $\begin{array}{c}2.2 \\
(0.2)\end{array}$ \\
\hline Below second rib, 5 in. & $\begin{array}{l}24.8 \\
(1.5)\end{array}$ & $\begin{array}{l}10.2 \\
(0.5)\end{array}$ & $\begin{array}{c}2.6 \\
(0.2)\end{array}$ \\
\hline
\end{tabular}

* Means and standard error of mean (in parentheses) are given. 


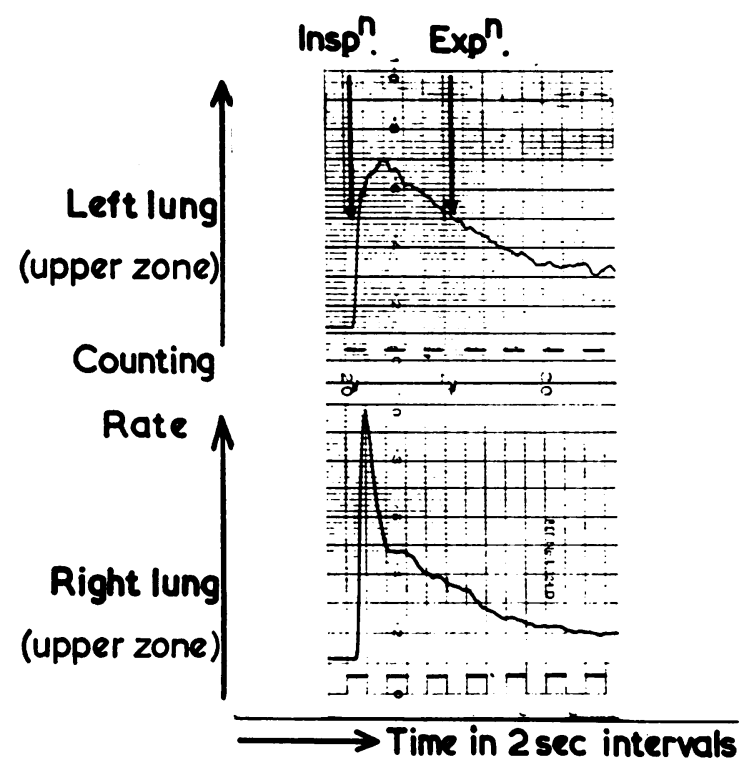

Fig. 2. Tracings from a patient with angiographic EVIDENCE OF AN ABSENT PULMONARY ARTERY ON THE LEFT, AND A VENTRICUlar SEPTAL DEFECT. The counters were at the level of the second intercostal space anteriorly. The slow clearance on the left is contrasted with the rapid clearance on the right, where recirculation of labeled blood interrupted the curve 3 seconds after the beginning of inspiration.

to the ventilation in each lung core. In this case, the relative ventilations, left to right, were 0.6 to 1. (In practice, radioactive oxygen rather than carbon dioxide is used for the ventilation measurements because it is removed much more slowly, and any error caused by slow inspiration is thus minimized.)

During the breath-holding period, the radioactive carbon dioxide was removed very rapidly on the right side, and the calculated clearance rate was 38 per cent per second, compared with the normal (adult) value of about 7 per cent per second at this level. This high value is explained by the passage of the whole cardiac output through the right lung augmented by the left to right shunt. Some 3 seconds after the beginning of inspiration, the rapid fall in counting rate on the right was interrupted by a transient rise in activity. This was caused by the recirculation of labeled blood through the lung and its early appearance is explained by the intracardiac shunt.

On the left the counting rate fell slowly. Close inspection shows that this occurred only after recirculation had begun and that during the first 3 seconds of breath-holding, the counting rate actually rose slightly, probably because of increasing radioactivity in the chest wall and bronchial circulations. The tracing suggests that the pulmonary blood flow was absent or very small.

At the end of the breath-holding period, any radioactivity remaining in the alveolar gas is washed out as the patient breathes room air. The counting rate which remains is due to radioactive blood and tissue.

Figure 3 shows the angiocardiogram of a 29

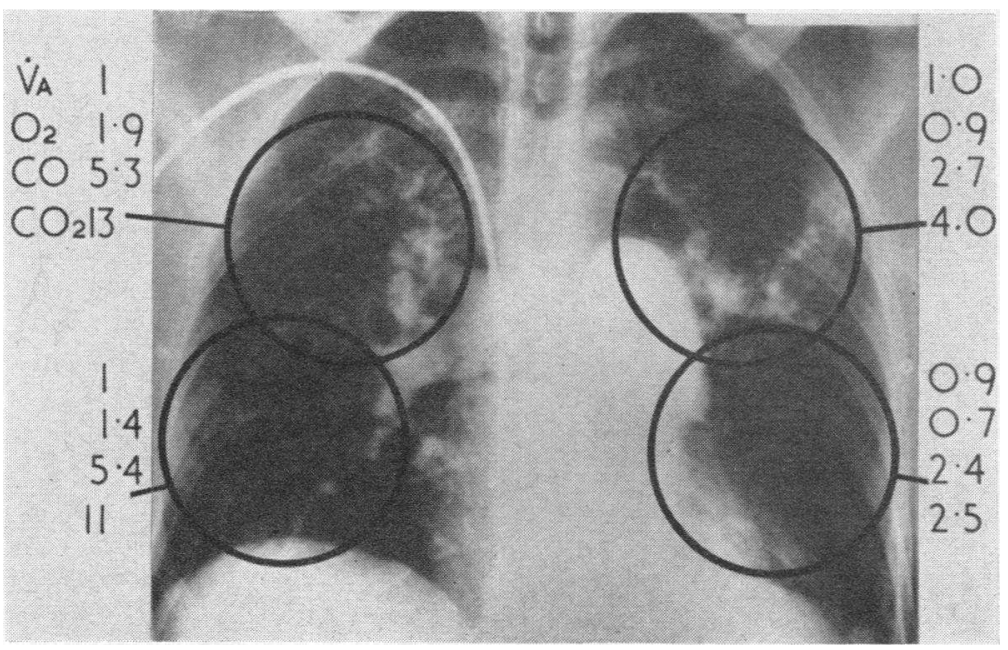

Fig. 3. Angiocardiogram of a patient with MUltiple pUlmonary EMBol. Circles show the lung cores from which counts were accepted. The figures are the radioactive carbon dioxide, carbon monoxide and oxygen clearance rates, and the relative ventilation (left to right) in each zone. 


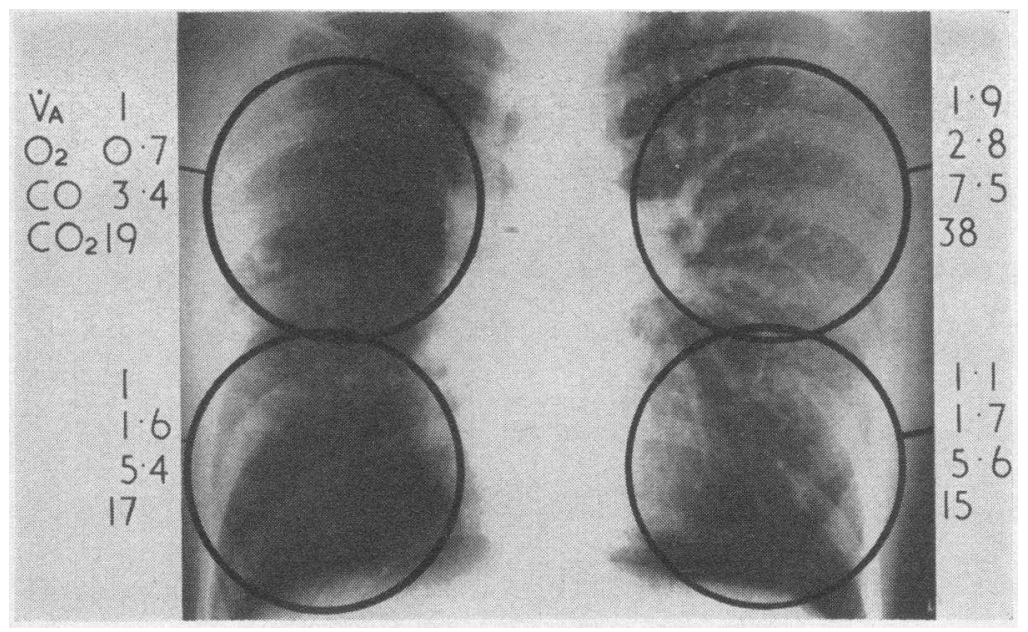

Fig. 4. Angiogram of patient who was thought to have a reduced BLOOD FLOW IN THE RIGHT LUNG. The radioactive measurements suggested, however, that the left lower lobe was also diseased, and review of the angiogram confirmed this.

year old engineer who had developed thrombophlebitis of the left calf 6 months previously, and had complained of a second episode in the left thigh 3 months before. He was admitted to hospital because of progressive shortness of breath on exertion. On several occasions he had coughed up clots of blood in the morning. The angiocardiogram was reported by Dr. R. Steiner as showing "gross enlargement of the main pulmonary artery and of the right and left branches. A few relatively normal caliber vessels were seen going into the right lower lobe, but elsewhere in the right lung, the peripheral vessels were of very narrow caliber and irregular in their course. There was virtually no arterial filling at the apex of the right lung. The left lung showed no filling whatsoever in the left lower zone, and sparse filling in the left upper zone. The appearances are consistent with multiple arterial thromboses and complete thrombosis of the main left lower lobe."

Measurements using radioactive carbon dioxide were made 6 days after the angiocardiogram when the clinical condition was unchanged. The counters were centered over the second rib anteriorly and 3 inches below this on both sides of the chest, and circles have been drawn on the radiograph to show the cylindrical cores of lung from which counts were accepted. The clearance rates of radioactive carbon dioxide, carbon monoxide and oxygen and the relative ventilations (right side taken as unity) are also shown on Figure 3. It can be seen that the clearance rates of all three gases were greatly reduced in the left lung compared with the right, although the ventilations on the two sides were comparable. The reduction in blood flow was apparently less marked in the left upper zone (carbon dioxide clearance rate 4.0 per cent per second) than in the left lower zone $(2.5$ per cent per second). Of the four zones examined, the right upper had the best function.

In general, the radioactive carbon dioxide clearance rates and the angiocardiogram indicated similar blood flow distributions. Both showed a very low blood flow at the left base and impaired perfusion of the left upper zone. The only discrepancy was the high clearance rate in the right upper zone where the angiocardiogram was reported as showing no filling at the right apex. This apparent disagreement was resolved when the films were examined because, whereas the extreme apex of the right lung received no dye, the upper zone in the region of the second rib was well perfused (Figure 3 ). The carbon monoxide and oxygen clearance rates correlated closely with the carbon dioxide clearance rates.

Good agreement between the radioactive carbon dioxide clearance rates and the angiogram was also seen in the case of a 29 year old nurse who had complained of increasing breathlessness on exertion, cough, and purulent sputum for many years. A diagnosis of unilateral transradiancy (6) on the right side had been made at another 
hospital because an angiogram showed reduced vascularity on that side. At thoracotomy, the surgeon reported some collapse of the main and lobar bronchi on the right and these were stiffened with wire. Some improvement apparently followed this, although the patient's mental state made objective assessment difficult. Her breathlessness subsequently increased and the possible benefit from right pneumonectomy was being considered when she was referred for assessment.

Measurements were made with the counters at the level of the second intercostal space and fourth rib anteriorly, and the results are summarized in Figure 4. They show that the clearance rates of radioactive carbon dioxide, carbon monoxide and oxygen, and the ventilation, were all greatly reduced in the right upper zone compared with the left. The function of both lower zones was very similar. The higher clearance rates in the left upper zone compared with both lower zones suggested that the latter also were diseased. When the angiogram films were re-examined, it became clear that the filling of the left lower lobe, as well as that of the right lung, was defective and that the apparently normal pattern at the left base had been caused by vessels in the lingula. In fact, the only well perfused part of the lung was the left upper lobe, and the correlation with the radioactive measurements was agreed to be excellent. Right pneumonectomy was not advised.
Figure 5 shows the radiograph of a 46 year old deputy foreman who complained of cough and progressive shortness of breath. Measurements were made with the counters at the level of the second and fifth ribs anteriorly and show that no gas entered the large cyst in the right lower zone. The clearance rates in the upper zones were of interest in that they were much increased (for example, the radioactive carbon dioxide clearance rates were both 18 per cent per second compared with the normal value of 4.8 per cent per second at this level). This is the usual finding in the presence of a large lesion elsewhere in the lung and presumably indicated a "compensatory" increase in local blood flow, when blood which had been diverted from the diseased area had opened up more capillaries.

This increased function in an apparently normal area in the presence of disease elsewhere in the lung makes the application of the normal data of Table I difficult in some instances. An example was a 40 year old slater and tiler who complained of dull pain in the left chest but no shortness of breath. He had a large cyst in the left upper zone occupying almost half of the left hemithorax, and the results of the measurements are summarized (Patient 1) in Table II. It can be seen that the clearance rates of radioactive carbon dioxide, carbon monoxide, and oxygen $(3.6,1.9$, and 0.4 per cent per second, respectively) in the

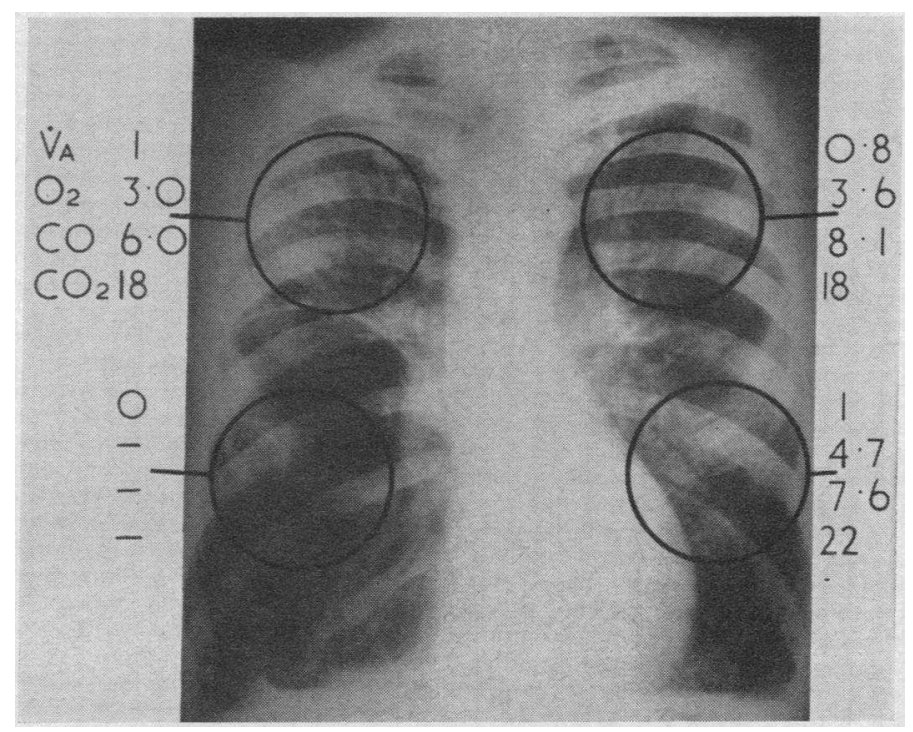

Fig. 5. Results from a patient with LARge CySt in the Right LOWER ZONE. 
J. B. WEST, C. T. DOLLERY AND P. HUGH-JONES

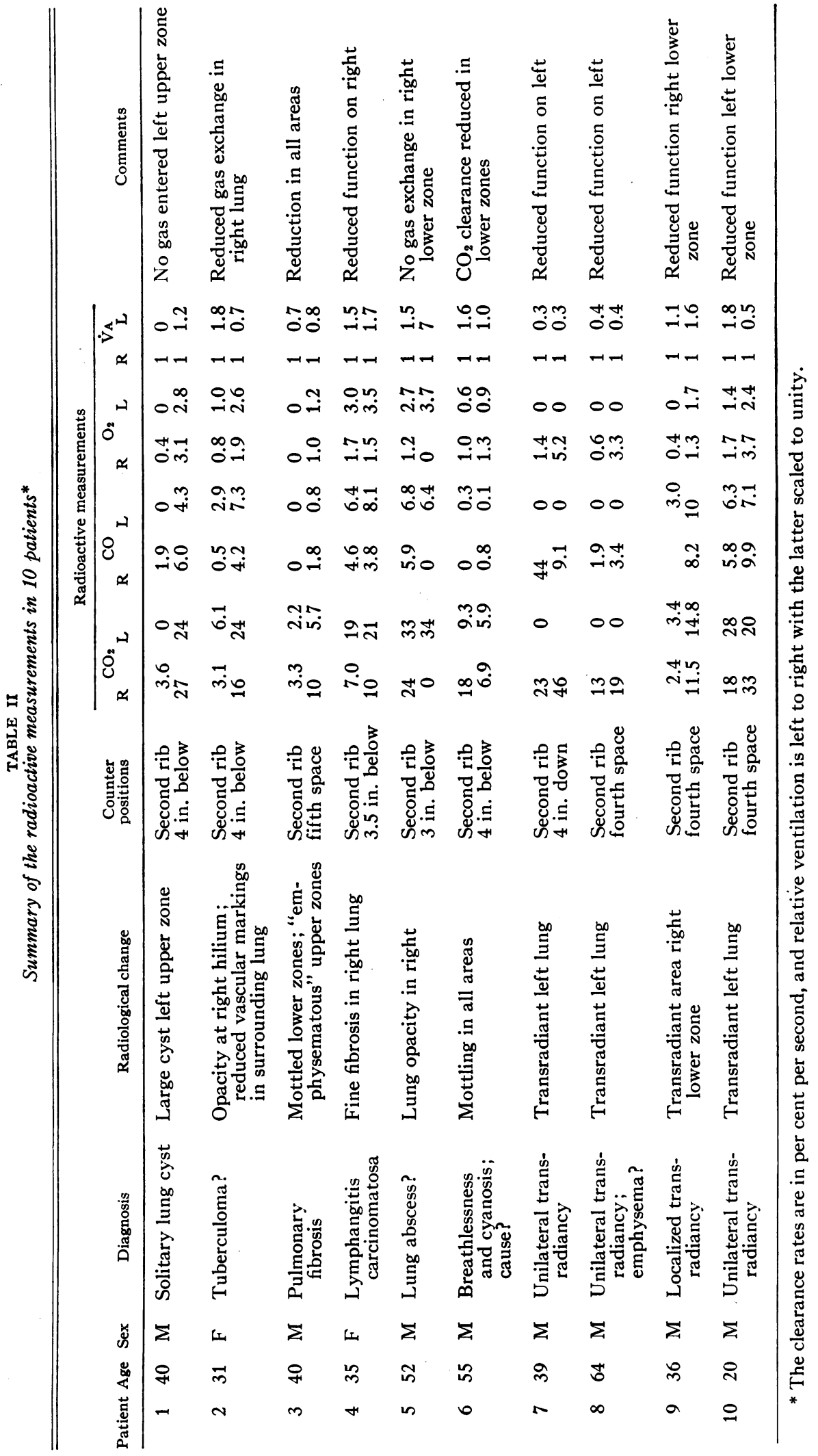


right upper zone were relatively normal according to Table I. However, because of the lack of "compensatory" increase in the right upper zone in the presence of such a large lesion on the left, tomographs of the right upper lobe were ordered. These showed further small cysts and the failure of the clearance rates to increase in this area was then explained. Thus the finding of "normal" clearance rates (on the criteria of Table I) was here evidence for local disease.

A different functional pattern in the presence of cysts is illustrated by Figure 6 which shows the radiograph of a 19 year old teleprinter operator. She had no respiratory symptoms but was referred following a mass miniature radiograph which showed large air-containing cysts in the right mid and lower zones of the chest. The results indicate that the ventilation in the right lower zone was greatly reduced compared with that in the left lower zone (ratio, 1 to 2.5). However, the clearance rates of carbon dioxide, carbon monoxide and oxygen were only slightly less on the right than the left. This disparity between the ventilation and clearance rates is compatible with a large nonventilating lesion at the right base surrounded by a thin shell of lung which had almost normal function. In these circumstances the initial counting rate would be grossly reduced, but the clear- ance rates which depend upon the blood flow and gas exchange per unit volume of ventilating lung would be normal. In the upper zones there were "compensatory" increases in clearance rates, less marked on the right where the ventilation was reduced, presumably because of interference by the cysts.

Figure 7 shows the bronchogram of a 39 year old housewife who had severe saccular bronchiectasis of the right lung with possibly some disease on the left. She had complained of much sputum and shortness of breath for many years and had suffered from recurrent respiratory infections. Pneumonectomy was contemplated and she was referred to establish the respiratory value of the right lung.

Measurements were made with the counters at the level of the second intercostal space and fifth rib anteriorly. The results show that the function of the right lower zone was grossly impaired. The clearance rates of radioactive carbon dioxide, carbon monoxide and oxygen were all exceedingly low, and the ventliation was about one-half that of the left lower zone. The function in the right upper zone was considerably less than that in the left upper zone, although the figures were not low by comparison with Table I. There is no doubt that this part of the lung was diseased as evi-

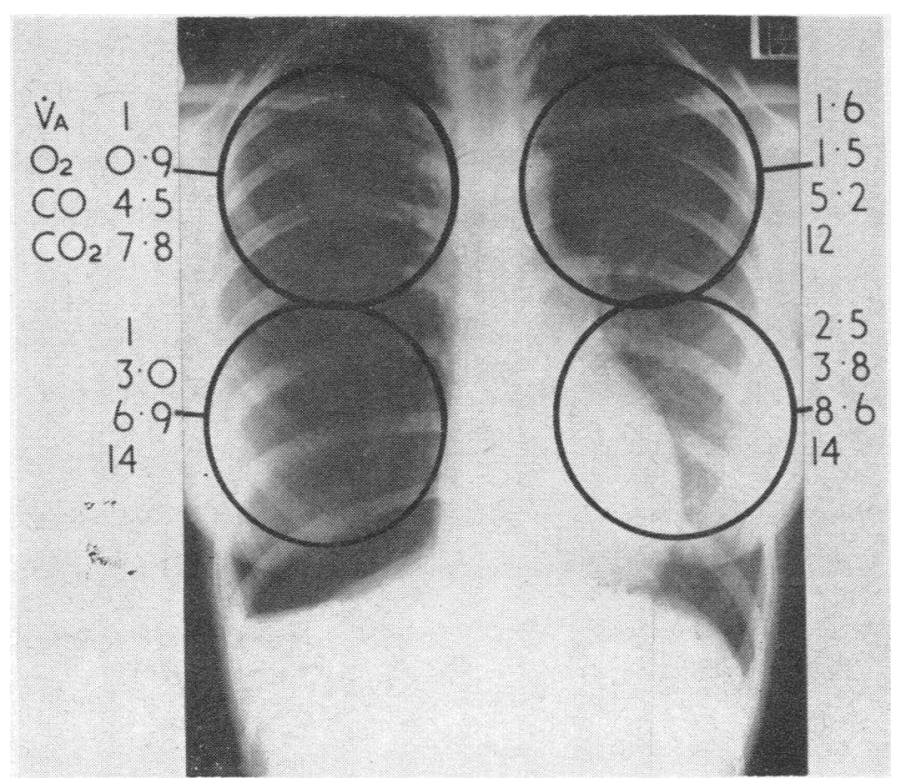

Fig. 6. Results from a patient with large cystic area in the RIGHT MID AND LOWER ZONES. 


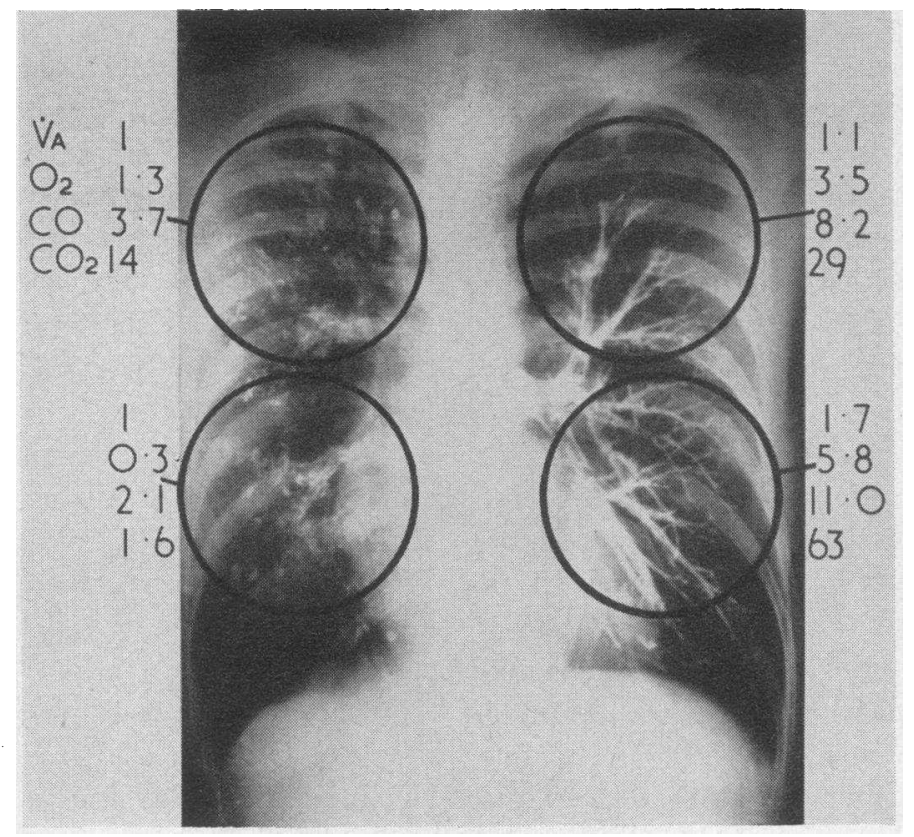

Fig. 7. Bronchogram of PATIENT With SEvERE BRoNChiectasis IN THE RIGHT LUNG.

denced by the bronchial dilatation shown on the bronchogram, but apparently sufficient lung reserve had opened up to give normal clearance rates. The clearance rates on the left side were all greatly increased.

Table II summarizes the findings on nine other patients on whom measurements were made in four zones of the lung using all three gases.

In order to determine the repeatability of the clearance rate measurements, 15 pairs of duplicate breaths for each of the three gases were analyzed in 12 consecutive patients who had been referred

TABLE III

Repeatability of clearance rates in 12 consecutive patients and 10 normal volunteers expressed as the average deviation of duplicates from their means (as a percentage)

\begin{tabular}{lccc}
\hline & $\begin{array}{c}\text { Radio- } \\
\text { active } \\
\text { carbon } \\
\text { dioxide }\end{array}$ & $\begin{array}{c}\text { Radio- } \\
\text { active } \\
\text { carbon } \\
\text { monoxide }\end{array}$ & $\begin{array}{c}\text { Radio- } \\
\text { active } \\
\text { oxygen }\end{array}$ \\
\hline Normal subjects & 7.2 & 7.1 & 12.6 \\
$\begin{array}{l}\text { (all counting positions } \\
\text { except second rib level) }\end{array}$ & 35.8 & 14.7 & 36.0 \\
$\begin{array}{c}\text { Normal subjects } \\
\text { (second rib level) }\end{array}$ & 6.7 & 10.7 & 11.2 \\
$\begin{array}{c}\text { Patients (all counting } \\
\text { positions) }\end{array}$ & & & \\
\hline
\end{tabular}

for examination, and the results are shown in Table III. In the normal use of oxygen ${ }^{15}$ some of the curves obtained are unsatisfactory, perhaps because the patient failed to empty the bag completely, or because he moved during the breathholding period, or for some other technical reason. Any such cases which would normally have been repeated (a very simple process for this test) were excluded from the repeatability series, the aim of which was to determine the reliability of measurements routinely accepted. Duplicate breaths for all three gases on the ten normal volunteers were also analyzed and the results are also shown in Table III. One breath was excluded, this being the first breath in a subject who showed initially high clearance rates for radioactive carbon dioxide which settled to normal values after a few minutes' rest in the chair (see Discussion).

It can be seen that in both patients and normal subjects, the repeatability of the radioactive carbon dioxide clearance rates was best, followed by the carbon monoxide and oxygen measurements. The reason for the larger variation in the oxygen clearance rates is that the slopes are small, and the statistical fluctuations in counting rate therefore cause more uncertainty when the line of visual best fit is drawn. Such counting 
rate fluctuations become increasingly less important as the clearance rate increascs. Dr. C. Natthews has calculated by an approximate method that for a counting rate of 2,000 counts per second, a ratemeter integrating time of 0.2 second and a breath-holding period of 10 seconds. the standard deviation of the slope of a line of best fit about a true slope of 2 per cent per second would be 0.2 per cent per second. This calculation cloes not include the effect of the time constant of the recording pen.

\section{DISCUSSION}

As a method for measuring regional blood flow in the lung, the use of radioactive carbon dioxide compares favorably with angiography or bronchospirometry. From the patient's point of view the test is simple and quick, and there is no associated discomfort. There are none of the obvious disadvantages of catheterization or intubation, and the only unphysiological feature is 10 seconds of breath-holding. As yet no patient has been so breathless that he could not cooperate satisfactorily. The measurements can easily be repeated at intervals, and the radiation hazard is small by the standards of diagnostic radiology.

An important practical limitation is that the oxygen ${ }^{15}$ must be prepared in the vicinity because it is so short-lived. While a cyclotron is not essential for this, a powerful particle accelerator or source of X-rays is necessary, and such expensive equipment is only likely to be available in the larger centers.

It is true that in many instances, a plain chest radiograph will give valuable information about regional blood flow. There may be an obvious area of fibrosis, for example, or vascular markings may be reduced. However, such appearances can be very misleading. In Patient 4 of Table II, the radiograph showed a very fine fibrosis on the right which was not at all obvious. This was thought at the time to be an early postradiation fibrosis, although the subsequent course proved it to be lymphangitis carcinomatosa following carcinoma of the breast. The radioactive carbon dioxide measurements showed that the blood flow had in fact been reduced to less than one-half, compared with the normal side.

Another example of poor correlation between radiographic appearances and the clearance rates was Patient 10 of Table II. This 20 year old National Serviceman had no symptrms, hut his chest radiograph showed obvious transradiancy of the whole of the left lung with diminished vascular markings in both upper and lower zones. As expected, the clearance rate of radioactive carbon dioxide was reduced in the left lower zone compared with the right, but surprisingly, the reverse was the case for the upper zones. The carbon monoxide clearance rate and ventilation were also higher in the left upper zone than in the right. It is difficult to explain these findings, which were confirmed on repeated observations, but it is clear that an area of the lung which appeared abnormal on the radiograph had, in fact, excellent function.

In some instances, the radiograph may show disease in several parts of the lung, and to assess the relative function on appearances alone may be impossible. Patient 3 was a 40 year old railwayman who had considerable disability, and whose radiograph showed a striking mottling of both lower zones and "emphysematous" upper zones. $\mathrm{He}$ was referred so that the relative contribution of the upper and lower zones (all of which had obvious disease) could be determined. The measurements showed that the pulmonary blood flow was reduced in all areas but that the right lower zone was the best of the four.

On theoretical grounds, the clearance rates of radioactive carbon dioxide will be affected by variations in cardiac output, and there is good evidence that excitement or apprehension causes high values. Exercise in normal subjects raises the clearance rates in the upper zones faster than in the lower zones (5), and the commonest artifact caused by nervous tachycardia is therefore unduly high clearance rates in the upper zones. As an example, the radioactive carbon dioxide clearance rate for the first breath of one of the normal subjects was 18 per cent per second at the level of the second rib, and 31 per cent per second 4 inches lower down. At this time his pulse rate was 106 per minute. The corresponding clearance rates after a few minutes' rest in the chair were 4.2 and 13.6 when his pulse rate had fallen to 84 . Such large variations are unusual but may cause considerable confusion unless care is taken to ensure a relatively basal state. It is possible that the 
high clearance rates seen in some cases (for example Figures 4 and 7 , and Patients 5 and 10 in Table II) may reflect high cardiac output resulting from excitement, or result from insufficient time allowed for the patient to recover from walliing to the clinical investigation room. In order to assess regional lung function in these instances, less reliance must be placed upon comparisons with the normal data of Table I than on relative clearance rates in different zones.

In some patients on whom measurements have been made, the clearance rates of radioactive carbon dioxide tended to be low in all areas of the lung. While this has been particularly common in patients with emphysema (which will be described elsewhere), Patient 3 in Table II and the patient whose angiocardiogram is shown in Figure 3 are examples. Inhaled radioactive carbon dioxide can be cleared only by pulmonary blood which is perfusing ventilated alveoli, so that appreciable shunting of blood through nonventilated lung may result in low carbon dioxide clearance rates. However, a more probable explanation in these patients is that there is so much blood flow inequality within the counting field that the shallow slopes of the poorly perfused areas predominate in the over-all clearance rate, although it can be shown that considerable inequality is necessary before this effect is appreciable. A general reduction in the clearance rates of radioactive carbon monoxide is associated, as would be expected, with a low over-all carbon monoxide diffusing capacity as measured by the single-breath test (7). For example, in Patient 6 of Table II, the carbon monoxide clearance rates were reduced in all areas and the over-all diffusing capacity was down to one-quarter of the expected value. A high correlation between regional and over-all carbon monoxide uptakes has also been seen in other patients with diffusing defects of the lung.

A feature of the results is the correlation in each subject between the clearance rates of the three gases in the four lung zones examined. The results set out in Figure 3 are a good example of this. The carbon dioxide clearance rate is highest in the right upper zone and then follows the right lower zone, left upper zone, and left lower zone in that order. Precisely the same order applies to the carbon monoxide and oxygen clearance rates. Other good examples can be found in Table II.

This correlation is not surprising when it is appreciated that the loss of the inhaled isotope from the counting field occurs in two stages. First, the tracer must be transferred from the alveolar gas to the pulmonary capillary blood, and second, the isotope must be removed by the local blood flow. In earlier work with oxygen ${ }^{15}$; it was thought that the fall in counting rate during breathholding chiefly gave information about the initial transfer, so that the oxygen clearance rate was taken as a measure of the local oxygen uptake (1) and the carbon monoxide clearance rate as a measure of the local diffusing properties of the lung (4). However, recent work has shown that the second stage-that is, the rate of removal of the tracer from the counting field by the local blood flow-is an important factor for all three gases so that all of the clearance rates are weighted by blood flow (8).

Oxygen ${ }^{15}$-labeled carbon dioxide is a particularly valuable gas, because its transfer from alveolar gas to capillary blood is exceedingly rapid. For this reason its clearance rate is, in practice, solely determined by the rate of removal of the blood from the counting field. The carbon dioxide clearance rate can therefore be used as a measure of the second stage for both oxygen and carbon monoxide, and this enables the initial stagethat is, the rate of transfer from alveolar gas to capillary blood-to be calculated (8).

When the calculations are made for each lung zone, using the data in Table II, the variations in radioactive carbon monoxide clearance rate can be shown, in many cases, to be caused not by differences in the initial transfer from alveolar gas, but by differences in the rate of removal of the blood from the counting field. In other words, the clearance rate variations are not reflecting inequality of local diffusing properties so much as differences in local blood flow. For example, in Figure 3 , the carbon monoxide clearance rates on the right were 5.3 and 5.4 per cent per second compared with 2.7 and 2.4 per cent per second on the left. By using the appropriate carbon dioxide clearance rates to extract the blood flow components, the alveolar disappearance rates on the right become equal to about 10 per cent per second, 
while on the left, the rates are even higher. Thus, the measured clearance rates chiefly reflect blood flow differences. Another example is Patient 1 in Table II in whom the carbon monoxide clearance rates in the right upper and lower zones were 1.9 and 6.0 per cent per second, respectively. After allowing for the large difference in blood flow in the two areas (carbon dioxide clearance rates of 3.6 and 27.6 per cent per second), the rates of transfer of carbon monoxide from the alveolar gas in the two zones become approximately equal (10 and 7 per cent per second).

The calculations for radioactive oxygen are less reliable, but the analysis using carbon dioxide clearance rates suggests that, in many instances, inequality of oxygen transfer from alveolar gas does remain. Indeed, this would be expected, since oxygen uptake is generally flow-limited.

The conclusions about the true inequality of carbon monoxide and oxygen transfer from alveolar gas must be regarded as tentative, because the calculations use two poorly repeatable measurements. However, the general correlation of the clearance rates of carbon dioxide, carbon monoxide and oxygen is easily appreciated in that all three are partly measuring blood flow.

Although in general the clearance rate of all three gases is reduced in an area of local disease, there are instances in which, for example, the radioactive carbon monoxide clearance rate is reduced out of proportion to the carbon dioxide clearance rate. Patient 6 in Table II was a 55 year old electrician who was referred because of breathlessness and cyanosis on exercise. The radiograph showed diffuse mottling in all areas, with little evidence of localized disease. The radioactive measurements indicated reduced ventilation in the right upper zone where there was no measurable carbon monoxide clearance although the carbon dioxide clearance rate was high. These findings were confirmed on repeated measurements and suggest a diffusing defect in a well perfused area caused, perhaps, by a thickened alveolar membrane. In addition there was a generalized reduction in radioactive carbon monoxide clearance rates and a low diffusing capacity measured by the single-breath test $(7 \mathrm{ml}$ per minute per $\mathrm{mm} \mathrm{Hg}$; normal range 21 to 36 ), all pointing to impaired diffusion.
SUM MARY

Carbon dioxide labeled with oxygen ${ }^{15}$ has been used to measure regional pulmonary blood flow in a series of 30 patients with a variety of lung diseases. The isotope has a half-life of only 2 minutes and is prepared in a cyclotron in the hospital grounds. For the patient, the measurement is very simple and the radiation dose is small. He takes a single breath of air containing a small quantity of active gas and breath-holds for 15 seconds. Scintillation counters placed in front of and behind the chest detect the activity of gas within the lung, and the clearance rate during breath-holding is a measure of the pulmonary blood flow in the lung core examined.

Good correlation was found between the radioactive measurements and angiograms in four patients, but the plain radiographs showed some interesting discrepancies in a further group. In most cases the radioactive carbon dioxide clearance rates were found to be closely related to radioactive oxygen and carbon monoxide clearance rates. Striking increases in local blood flow were found in apparently normal areas in the presence of disease elsewhere in the lung, and this complicates a comparison with clearance rates determined from normal subjects. The use of radioactive carbon dioxide for measuring regional blood flow compares favorably with the traditional techniques of angiography and bronchospirometry.

\section{ACKNOWLEDGMENTS}

The authors wish to thank the Director and staff of the M.R.C. Radiotherapeutic Research Unit for facilities for this work, and Mr. P. Buckingham and Mr. G. Forse for technical assistance. The work was supported by the Medical Research Council.

\section{REFERENCES}

1. Dyson, N. A., Hugh-Jones, P., Newbery, G. R., and West, J. B. The preparation and use of oxygen-15 with particular reference to its value in the study of pulmonary malfunction. Proceedings of Second U.N. International Conf. on Peaceful Uses of Atomic Energy. Isotopes in Medicine, 1958, 26, 103.

2. Dyson, N. A., Hugh-Junes, P., Newbery, G. R., Sinclair, J. D., and West, J. B. Studies of regional lung function using radioactive oxygen. Brit. med. J. 1960, 1, 231. 
3. Dyson, N. A., Sinclair, J. D., and West, J. B. Comparison of the uptakes of oxygen-15 and oxygen-16 in the lung. J. Physiol. (Lond.) 1960, 152, 325.

4. Dollery, C. T., Dyson, N. A., and Sinclair, J. D. Regional variations in the uptake of radioactive $\mathrm{CO}$ in the normal lung. J. appl. Physiol. 1960, 15, 411.

5. West, J. B., and Dollery, C. T. Distribution of blood flow and ventilation-perfusion ratio in the lung, measured with radioactive $\mathrm{CO}_{2}$. J. appl. Physiol. 1960, 15, 405.
6. Macleod, W. M. Abnormal transradiancy of one lung. Thorax 1954, 9, 147.

7. Ogilvie, C. M., Forster, R. E., Blakemore, W. S., and Morton, J. W. A standardized breath holding technique for the clinical measurement of the diffusing capacity of the lung for carbon monoxide. J. clin. Invest. 1957, 36, 1.

8. Holland, R. A. B., West, J. B., and Dollery, C. T. Interpretation of radioactive gas clearance rates in the lung. To be published.

\section{SPECIAL NOTICE TO SUBSCRIBERS}

Post Offices will no longer forward the Journal when you move. Please notify The Journal of Clinical Investigation, Business Office, 333 Cedar Street, New Haven 11, Conn., at once when you have a change of address, and do not omit the zone number if there is one. 